\title{
PROTOCOLO DE AVALIAÇÃO DE MUDANÇA PARA O PROCESSO DE ESTERILIZAÇÃO A VAPOR*
}

\author{
Change assessment protocol for steam sterilization process
}

Protocolo de evaluación para el proceso de esterilización a vapor

Natalia Barbosa Ferreira de Moura do Santos ${ }^{1}$, Andrea Alfaya Acuna², Cristina Silva Sousa ${ }^{2 * *}$

RESUMO: Objetivo: Relatar a experiência da criação de um protocolo de avaliação de mudança do processo de esterilização a vapor. Método: Relato de experiência, com base no fundamento teórico e na validação de novos equipamentos do Centro de Material e Esterilização. A validação ocorreu entre maio e julho de 2016, e testou a adequação ao processo e ao material, utilizando a NBR ISO 17665-1. O protocolo contempla os principais pontos para influenciar a decisão de manter ou reavaliar o equipamento. A validação do protocolo ocorreu por cinco enfermeiros atuantes no Centro de Material e Esterilização. Resultados: O protocolo foi composto por seis ações, que exigem requalificação do equipamento, e três ações que não impactaram em nenhum ponto crítico do processo. O ponto mais crítico observado ocorreu com materiais úmidos. O protocolo foi validado pelos enfermeiros do Centro de Material e Esterilização e apresentado na forma de fluxograma. Conclusão: O protocolo favorece que enfermeiros atuem de forma crítica na manutenção corretiva e preventiva do equipamento de esterilização a vapor.

Palavras-chave: Esterilização. Vapor. Equipamentos e provisões hospitalares. Enfermagem perioperatória.

ABSTRACT: Objective: To report on the experience of creating a protocol, which evaluates changes in the steam sterilization process. Method: Experience report, based on the theoretical basis and validation of new equipment at the Central Sterile Supply Department. The validation occurred between May and July of 2016, and tested the suitability of the process and the material, using ISO 17665-1. The protocol includes main points that influence the decision of whether to maintain or re-evaluate the equipment. The protocol validation was carried out by five nurses from the Central Sterile Supply Deparment. Results: The protocol was composed of six actions, which required verification of the equipment, and three actions that did not impact any critical points in the process. The most critical point observed was with wet materials. The protocol was validated by the nurses from the Central Sterile Supply Department, and presented as a flowchart. Conclusion: The protocol promotes the idea of nurses acting critically in corrective and preventive maintenance of steam sterilization equipment. Keywords: Sterilization. Steam. Equipment and supplies, Hospital. Perioperative nursing.

RESUMEN: Objetivo: Informar la experiencia de la creación de un protocolo de evaluación del proceso de esterilización a vapor. Método: Relato de experiencia, basado en el fundamento teórico y en la validación de nuevos equipos del Centro de Material y Esterilización. La validación ocurrió entre mayo y julio de 2016, y probó la adecuación al proceso y al material, utilizando la NBR ISO 17665-1. El protocolo contempla los principales puntos para influir en la decisión de mantener o reevaluar el equipo. La validación del protocolo fue realizado por cinco enfermeros actuantes en el Departamento Central de Abastecimiento de Esterilización. Resultados: El protocolo fue compuesto por seis acciones, que exigen recalificación del equipo, y tres acciones que no impactan en ningún punto crítico del proceso. El punto más crítico observado ocurrió con materiales húmedos. El protocolo fue validado por los enfermeros del Departamento Central de Abastecimiento de Esterilización y presentado en forma de diagrama de flujo. Conclusión: El protocolo favorece que los enfermeros actúen de forma crítica en el mantenimiento correctivo y preventivo del equipo de esterilización a vapor. Palabras clave: Esterilización. Vapor. Equipos y suministros de hospitales. Enfermería perioperatoria.

*Trabalho de conclusão de curso da Pós-Graduação modalidade Residência em Centro Cirúrgico, e Centro de Material e Esterilização do Instituto Sírio-Libanês de Ensino e Pesquisa. 'Enfermeira pela Pontifícia Universidade Católica de Goiás (PUC-GO); especialista em Centro Cirúrgico e Centro de Material e Esterilização pelo Instituto Sírio-Libanês de Ensino e Pesquisa - São Paulo (SP), Brasil.

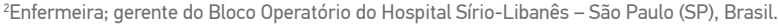

${ }^{3}$ Doutora em Ciências da Saúde pela Escola de Enfermagem da Universidade de São Paulo (USP); enfermeira assistencial do centro cirúrgico do Hospital Sírio-Libanês - São Paulo (SP), Brasil.

**Autor correspondente: crissousa@usp.br

Recebido: 23/10/2017 - Aprovado: 09/03/2018

DOI: 10.5327/Z1414-4425201800020008 


\section{INTRODUÇÃO}

De acordo com a Resolução da Diretoria Colegiada (RDC) da Agência Nacional de Vigilância Sanitária (ANVISA) n ${ }^{\circ}$ 15, de 15 de março de 2012, faz-se obrigatória a padronização dos diversos processos que ocorrem dentro de um Centro de Material e Esterilização (CME). Os centros são classificados como CME classe I e CME classe II, e têm a finalidade de instituir boas práticas para processamento de produtos para saúde (PPS) ${ }^{1}$. No artigo 37 dessa norma, é descrita a necessidade de realização da qualificação de instalação, da qualificação de operação e da qualificação de desempenho para os equipamentos utilizados na limpeza automatizada e na esterilização de PPS, com periodicidade mínima anual. Esses componentes compõem o processo de validação do equipamento ${ }^{2}$.

A validação da esterilização depende de um conjunto de etapas denominadas qualificação, com certificação da adequabilidade dos parâmetros avaliados. Entre elas, encontrase a validação do desempenho do equipamento esterilizante, que é realizada por controles físicos, químicos e biológicos, tendo como finalidade garantir que a probabilidade de sobrevivência de micro-organismos seja menor do que 1:1.000.000 $\left(10^{-6}\right)^{3,4}$. Assim, qualificação é definida como o conjunto de ações realizadas para atestar e documentar que quaisquer instalações, sistemas e equipamentos estão propriamente instalados e/ ou funcionam corretamente, conduzindo aos resultados esperados. A qualificação é parte da validação, mas as etapas da qualificação não constituem, isoladamente, a validação do processo ${ }^{5}$.

A esterilização é o processo de destruição de micro-organismos a tal ponto que não seja mais possível detectá-los em meio de cultura padrão, no qual previamente se proliferaram ${ }^{3,6}$. Pode ser realizada por meios físicos, químicos e físico-químicos. Entre os processos físicos, encontra-se a esterilização por vapor saturado sob pressão.

Esse monitoramento da esterilização deve abranger as avaliações física, química e biológica dos processos. O controle físico compreende o monitoramento dos parâmetros críticos de cada processo, por meio de registro manual ou por impressora interligada ao esterilizador. Para o controle químico são utilizados indicadores e integradores com diferentes apresentações no mercado. Os indicadores biológicos são caracterizados por uma preparação padronizada de esporos bacterianos projetados para produzir suspensões com $10^{5} \mathrm{a}$ $10^{6}$ esporos por unidades de papel-filtro ${ }^{7}$.

Teoricamente, um ciclo de esterilização padrão por calor úmido é dividido em três fases ou etapas ${ }^{1}$ : acondicionamento, na qual ocorre a remoção de ar da câmara interna da esterilizadora e o pré-aquecimento da carga; exposição ou esterilização, em que ocorre o contato do vapor com o material em condições controladas de pressão e temperatura, para promover a morte ou a inativação dos micro-organismos viáveis; e secagem, responsável pela remoção do vapor e condensado de vapor do interior da carga.

A validação é a prova documentada de que o equipamento de esterilização é efetivo e reprodutível. As questões de reprodutibilidade são fundamentais para um processo de validação bem definido; portanto, é importante que o hospital tenha definidos e aprovados seus protocolos de trabalho e é desejável que haja um sistema de qualidade operante implementado, para assegurar a capacitação dos procedimentos e sua reprodutibilidade ${ }^{5}$.

O processo de validação consiste nas seguintes etapas ${ }^{5}$ :

1. qualificação do projeto: antes de adquirir o equipamento, as exigências do fabricante para sua instalação devem ser conhecidas;

2. qualificação da instalação: evidência documentada, fornecida pelo fabricante ou distribuidor, de que o equipamento foi entregue e instalado de acordo com as especificações;

3. qualificação da operação: evidência documentada, fornecida pelo fabricante ou distribuidor, de que o equipamento, após a qualificação da instalação, opera dentro dos parâmetros originais de fabricação;

4. qualificação de desempenho: evidência documentada de que o equipamento, após as qualificações de instalação e operação, apresenta desempenho consistente por, no mínimo, três ciclos sucessivos do processo, com parâmetros idênticos, utilizando-se pelo menos a carga de maior desafio, determinada pelo serviço de saúde.

Independentemente do método de esterilização, o equipamento deve ser aprovado pela ANVISA, validado pela empresa fabricante no momento da instalação, requalificado no mínimo anualmente e monitorado antes de utilizado rotineiramente, além de manutenções preventivas e de reparo feitas pela engenharia hospitalar ou pelo fabricante do equipamento 5 .

\section{OBJETIVO}

Relatar a experiência da criação de um protocolo de avaliação de mudança para o processo de esterilização a vapor. 


\section{MÉTODO}

Trata-se de um relato de experiência da criação de um protocolo de avaliação de mudança para o processo de esterilização a vapor em um hospital de grande porte, filantrópico, localizado no município de São Paulo. O protocolo foi construído a partir de fundamentação teórica ${ }^{8}$, normas e resoluções e acompanhamento do processo de validação dos novos equipamentos do CME.

Para o novo CME, inaugurado em agosto de 2016, foram adquiridos equipamentos de grande capacidade produtiva e baixo custo de operação, com o objetivo de aperfeiçoar a logística em relação ao abastecimento de materiais e melhorar a estrutura de trabalho, com foco na saúde e na segurança do paciente e do colaborador'.

Em março de 2016, junto à enfermeira coordenadora do CME, observou-se a necessidade de desenvolver este trabalho. A enfermagem não deve atuar somente durante $o$ processamento do material, mas também quando o equipamento passa por modificações e quando apresenta problemas. Daí surgiu a questão que norteia o presente trabalho: Quando requalificar? Será que as enfermeiras sabem disso? A partir desses questionamentos, os enfermeiros buscaram informações sobre como é o processo de validação de um equipamento e por três vezes acompanharam a qualificação de desempenho das autoclaves, visto que a qualificação operacional já estava em processo.

A implantação de um novo CME, com instalação de novos equipamentos de esterilização a vapor (Century v120 e Evolution HC1000), requer validação e qualificação de seus processos antes de iniciar o funcionamento da unidade.

É necessária a realização do processo de validação dos equipamentos de esterilização a vapor pelo fabricante - a empresa Steris, que é responsável pela qualificação de instalação e qualificação térmica. A calibração térmica do equipamento é realizada pela empresa Escala e a qualificação de desempenho, pela empresa Orion, ambas contratadas pela unidade hospitalar. Esses passos são essenciais para o funcionamento correto do equipamento e para a liberação do seu uso.

Foram elencados os profissionais envolvidos nos processos de qualificação das autoclaves. A empresa Steris foi representada pelos profissionais: supervisor de serviço, responsável técnica e especialista clínica. A empresa Escala, responsável pela calibração, foi representada pelos técnicos operacionais; e a empresa Orion, que faz a qualificação de desempenho do equipamento, foi representada pelos técnicos de campo e pelo seu sócio-diretor. As equipes de manutenção e engenharia clínica do hospital e a equipe de enfermagem do CME - composta da coordenadora, da enfermeira líder, da enfermeira residente e de técnicos de enfermagem - também foi envolvida em todo o processo.

Para o processo de qualificação, é requerido seguir normas que regem a condução do trabalho de forma adequada. Para tal, seguem-se as normas do fabricante, normativas nacionais e também normativas internacionais - traduzidas e usadas no país - , como a RDC n. $15^{2}$ e a NBR ISO n. $17.665-1^{10}$. Esse processo deve ser desenvolvido dentro do CME da unidade hospitalar.

Dessa forma, no período de maio a julho de 2016, ocorreu o processo de validação. Para a qualificação de desempenho ser efetiva, devem ser feitos os seguintes testes: leak test, três ciclos de esterilização vazios, Bowie Dick, e três ciclos de esterilização sem carga. Todos os ciclos são monitorados com termômetros colocados em pontos específicos do equipamento, que avaliam os pontos do processo.

Ao final desse processo, iniciou-se a construção do protocolo, pelas autoras, com o objetivo de contemplar os principais pontos para direcionar a decisão de manter ou reavaliar o equipamento.

Posteriormente, a validação do protocolo ocorreu pelos enfermeiros do CME, por meio de leitura do material construído. Esses profissionais foram questionados sobre compreensão, clareza e facilidade de leitura do fluxograma.

O processo de criação do protocolo de avaliação de mudança foi finalizado e apresentado à equipe de enfermagem do CME, impresso em papel sulfite A3 e disponibilizado na área de preparo da unidade.

\section{RESULTADOS}

No dia 25 de maio de 2016, foram iniciadas as qualificações de desempenho dos equipamentos, estando presentes os técnicos da empresa Orion, os representantes da empresa Steris, os técnicos de enfermagem do CME e a enfermeira líder da unidade. Nessa data, logo nos primeiros testes, houve problemas com a carga molhada, o que impossibilitou a realização dos testes, de modo que as atividades precisaram ser encerradas. Os motivos para a carga molhada podem ser: tubulação, equipamento, vácuo e curva de aquecimento. 
O retorno da qualificação de desempenho aconteceu no dia 15 de junho de 2016, tendo início pelo equipamento número 02 , que possui ciclo para príons. Foram realizados os testes descritos anteriormente, tanto para um ciclo normal como para o ciclo de príons, ou seja, foram realizados seis testes sem carga e seis testes com carga. Foram necessários três dias para finalizar o processo de execução dessa qualificação de desempenho.

Em 22 de junho de 2016, as autoclaves de números 02 e 03 foram aprovadas, e a enfermeira líder acompanhou o segundo dia de testes na autoclave número 04 . Os técnicos da empresa Orion instalaram os termômetros no equipamento e acompanharam, pelo notebook, sua curva de aquecimento. Primeiramente foram realizados os testes sem carga, depois foram iniciados os testes com carga. Os materiais utilizados foram preparados e embalados pelos técnicos do CME.

O equipamento número 01 foi submetido aos testes em 23 de junho de 2016. O ciclo expresso foi excluído nesse processo por sua falta de uso pela instituição, e a aprovação dos demais ciclos transcorreu sem intercorrências.

Após a fase de qualificação de desempenho, foi concluída a validação dos equipamentos e as autoclaves foram liberadas para uso. O tempo estabelecido de esterilização é 4 minutos, à temperatura de $134^{\circ} \mathrm{C}$, e 40 minutos de secagem para embalagens em tecido não tecido (TNT) ou papel grau cirúrgico e, para o ciclo de containers, foram estabelecidos 20 minutos de secagem. Em casos de materiais que correspondem a ciclo especial, devem transcorrer 90 minutos de secagem.

Em outubro de 2016, foram analisados os documentos de validação, registradas as datas e as fases da validação, adquirida a NBR ISO $17.665-1^{10} \mathrm{e}$, a partir desse momento, iniciada a confecção do protocolo. Ao final desse mês, o protocolo foi finalizado e apresentado para a coordenadora da unidade para validação de leiaute e conteúdo.

Após a validação pela coordenadora, foram necessárias alterações no formato do fluxograma para melhorar a compreensão e a inserção dos pontos que levariam à requalificação e a identificação de quais pontos não causariam nenhum impacto, podendo requerer apenas manutenção corretiva ou preventiva.

Em novembro de 2016, uma nova versão do fluxograma foi apresentada para a coordenadora da unidade, sendo necessária uma nova reformulação. Dessa vez foi solicitada a alteração de coloração do fluxograma, para que, com isso, ele ficasse mais compreensível, e a mudança de algumas sentenças, para dar melhor sentido às frases.
No fim de novembro, a versão reformulada do fluxograma (Figura 1) foi apresentada às enfermeiras do CME para validação de compreensão, avaliação de clareza e aplicabilidade, por meio de conversa informal.

Não houve alterações após essa fase, e o fluxograma foi impresso e disponibilizado em papel A3 colorido na área de preparo, próxima à autoclave e à localização das enfermeiras do CME, para ser utilizado como instrumento direcionador no processo de avaliação de mudança da autoclave.

\section{DISCUSSÃO}

Os resultados deste trabalho demonstram que o processo de avaliação de mudança é complexo e requer envolvimento da equipe de enfermagem em todas as fases.

Dentre as dificuldades vivenciadas nesse período, compreender o processo do equipamento, as possíveis falhas no processo de validação e a parametrização dos processos de esterilização foi desafiador para concluir a construção do fluxograma.

O processo de validação, incluindo a qualificação de equipamentos para esterilização realizada por empresas prestadoras de serviços de validação, tem evoluído nos últimos anos. O processo de esterilização por autoclave é basicamente o mesmo desde sua criação, em 1880, pelo pesquisador Charles Chamberland. Pode-se afirmar que a evolução no equipamento se deu no controle das fases do ciclo de esterilização, a partir de dispositivos de segurança e registro, e, na parte documental, surgiram exigências sobre o sistema de gestão da qualidade da esterilização ${ }^{11}$.

Nos dias atuais, é imprescindível que os CMEs das instituições de assistência à saúde validem o seu processo de esterilização, incluindo a qualificação do equipamento esterilizador. Para tanto, é necessário escolher uma norma técnica que será utilizada como referência para a elaboração e a execução dos protocolos para validação. Outras normas poderão ser adotadas em conjunto com a principal, como uso de referências para critérios de aceitação, procedimentos e indicadores, assim como recomendações técnicas de associações de classe e do fabricante ${ }^{11}$.

Os protocolos para validação deverão informar todos os procedimentos a serem realizados e os resultados esperados de cada etapa do processamento dos PPS, incluindo a justificativa para cada critério de aceitação adotado. Deverão ser fornecidos meios de comprovar que esses critérios vão garantir que, quando alcançados, os materiais processados no equipamento estarão esterilizados. Essa comprovação como 
indicador de resultado deverá ser obtida por meio de testes de esterilidade, que correspondem aos indicadores biológicos ${ }^{11}$.

A escolha da norma técnica a ser seguida deve tomar como base a data de publicação, pois é imperativo utilizar uma norma mais recente e, preferencialmente, já traduzida oficialmente para a língua portuguesa. Para a autoclave a vapor, a norma aplicada é a Associação Brasileira de Normas Técnicas (ABNT) NBR ISO 17.665-1 ${ }^{10}$, que entrou em vigor dia 22 de fevereiro de 2010. Essa norma é a tradução na íntegra da norma internacional ISO 17.665-1:2006, e cancela/ substitui a ABNT NBR ISO 11.134:2001 ${ }^{11}$.

Como a validação do processo de esterilização possui várias etapas, é permitido pela norma que elas sejam concluídas em ordem aleatória, não havendo a obrigatoriedade da conclusão satisfatória de uma etapa para que a próxima seja iniciada. O importante é que todas as etapas sejam concluídas satisfatoriamente ${ }^{11}$.

Na NBR ISO $17.665-1^{10}$, o item $12.5 \mathrm{diz}$ que qualquer mudança deve ser avaliada quanto ao seu impacto sobre a efetividade do processo de esterilização. Mudanças a serem consideradas — se aplicáveis — devem incluir:

1. reposição de uma peça que poderia fazer com que um parâmetro do processo se alterasse;

2. reposição de uma peça que poderia provocar aumento no vazamento para dentro da câmara de esterilização;

3. variação da homogeneidade na câmara de esterilização;

4. programa e/ou controlador modificado;

5. qualquer mudança no parâmetro do processo;

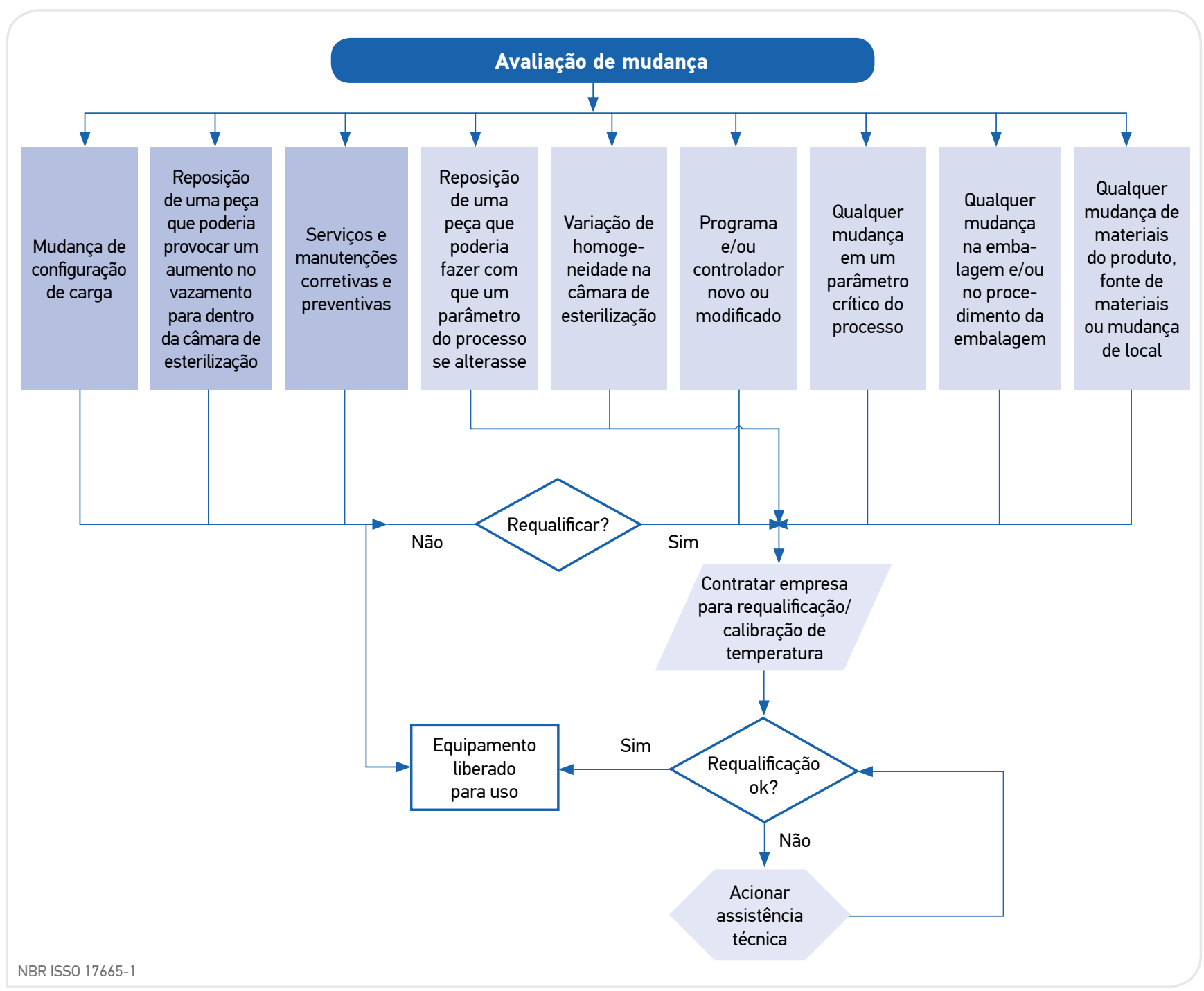

Figura 1. Fluxograma para Protocolo de Avaliação de Mudança na Esterilização a Vapor. 
6. qualquer mudança nos serviços e nos resultados de manutenção de um serviço;

7. qualquer mudança na embalagem e/ou no procedimento da embalagem;

8. qualquer mudança na configuração da carga;

9. qualquer mudança de materiais do produto, fonte de materiais ou projeto.

O resultado dessa avaliação deve ser documentado, incluindo a justificativa pelas decisões tomadas e a extensão de mudanças feitas nos requisitos do processo de esterilização, produto ou requalificação requerida (se aplicável $)^{10}$.

É recomendável a criação de um grupo de validação, composto de equipes de enfermagem do CME, engenharia e manutenção, fornecedores e prestadores de serviços, os quais precisam ter qualificação profissional comprovada para execução de suas atividades, para elaborar e executar os protocolos de qualificação, controle de mudanças e monitoramento dos equipamentos ${ }^{1}$.

\section{CONSIDERAÇÕES FINAIS}

Este trabalho permitiu verificar a importância do processo de validação e a sua aplicação no cenário de trabalho da enfermagem. A produção do protocolo vem de encontro ao interesse da enfermagem de ser mais atuante em todos os processos dentro do CME. Como peça-chave no processo de recebimento e entrega de materiais estéreis, o enfermeiro deve buscar embasamento teórico e ter voz ativa no processo de qualificação dos equipamentos de esterilização a vapor.

Apesar da pertinência do tema no cenário atual, é necessário considerar que a enfermagem pouco se envolve no processo de requalificação do equipamento, deixando o assunto para a equipe de manutenção e/ou para a engenharia hospitalar. Portanto, além de ter despertado nas enfermeiras da unidade um olhar crítico frente ao processo, torna-se necessário desenvolver, a partir deste protocolo, um indicador que avalie sua aplicabilidade no dia a dia de trabalho da enfermagem.

\section{REFERÊNCIAS}

1. Miguel EA, Laranjeira PR. Validação e montagem de carga desafio: da teoria à prática. Rev SOBECC. 2016;21(4):213-16. https://doi. org/10.5327/Z1414-4425201600040007

2. Brasil. Agência Nacional de Vigilância Sanitária. Resolução da Diretoria Colegiada RDC no 15, de 15 de março de 2012. Dispõe sobre requisitos de boas práticas para o processamento de produtos para saúde e dá outras providências. Diário Oficial da União [Internet]. 15 mar 2012 [citado em 20 out; 2016]. Disponível em: http://bvsms.saude.gov.br/ bvs/saudelegis/anvisa/2012/rdc0015_15_03_2012.html

3. Associação Brasileira de Enfermeiros de Centro Cirúrgico, Recuperação Anestésica e Centro de Material e Esterilização. Diretrizes de práticas em enfermagem cirúrgica e processamento de produtos para a saúde. 7a ed. Barueri: Manole; 2017.

4. Calicchio LG, Laranjeiras PR. Controle da esterilização: monitoramento e validação do processo. In: Padoveze MC, Graziano KU, eds. Limpeza, desinfecção e esterilização de artigos em unidades de saúde. $3^{\mathrm{a}}$ ed. São Paulo: APECIH; 2010. p.193-217.

5. Cabral ALR, Davel GSCR, Calicchio LG. Esterilização. In: Silva MVG, Oliveira AC, eds. Teoria e prática na prevenção da infecção do sítio cirúrgico. Barueri: Manole; 2015. p.65-99.

6. Graziano KU. Processos de limpeza, desinfecção e esterilização de artigos odonto-médico-hospitalares e cuidados com o ambiente cirúrgico. In: Lacerda RA, ed. Controle de infecção em centro cirúrgico: fatos, mitos e controvérsias. São Paulo: Atheneu; 2003.

7. Tipple AFV, Pires FV, Guadagnin SVT, Melo DS. O monitoramento de processos físicos de esterilização em hospitais do interior do estado de Goiás. Rev Esc Enferm USP. 2011;45(3):751-7. http:// dx.doi.org/10.1590/S0080-62342011000300029

8. Caleman G, Lima VV, Oliveira MS, Massaro A, Gomes R, Silva SF, et al. Projeto aplicativo: termos de referência. São Paulo: Ministério da Saúde/Instituto Sírio-Libanês de Ensino e Pesquisa; 2016. 54p.

9. Acuna AA. Segurança e inovação no novo centro de material e esterilização do Hospital Sírio-Libanês. Rev Mel Prát [Internet]. 2015 [citado em 16 jul. 2016]. Disponível em: http:// revistamelhorespraticas.com.br/novo2015/admin/uploads/ indice_42a8e09acf3cac2481eca51dfff24479.pdf

10. Associação Brasileira de Normas Técnicas. NBR ISO 17665-1. Esterilização de produtos para saúde - Vapor - Parte 1: Requisitos para o desenvolvimento, validação e controle de rotina nos processos de esterilização de produtos para saúde. Rio de Janeiro: ABNT; 2010.

11. Calicchio LG, Laranjeira PR, Graziano KU, Moriya GAA. Controle de esterilização e desinfecção. In: Graziano KU, Silva A, Psaltikidis EM, eds. Enfermagem em centro de material e esterilização. Barueri: Manole; 2011. p.204-36. 